\title{
Zolpidem pharmacokinetics and pharmacodynamics in metabolic interactions involving CYP3A: sex as a differentiating factor
}

\author{
Wieslaw Jerzy Cubala • Mariusz Wiglusz • \\ Anna Burkiewicz • Maria Gałuszko-Wegielnik
}

Received: 3 May 2010 / Accepted: 28 May 2010 / Published online: 16 June 2010

(C) The Author(s) 2010. This article is published with open access at Springerlink.com

Keywords Zolpidem · Sex · Pharmacokinetics · CYP3A

To the editor:

We read with interest the recent paper by Polasek et al. on the evaluation of zolpidem as a mechanism-based inactivator of human CYP3A in vitro that was accompanied by the assessment of its metabolic interaction potential with CYP3A drugs [1]. The article clearly points out the mechanism of inactivation of human CYP3A in vitro and describes the implications of this mechanism for the in vivo metabolic interactions involving CYP3A. Given the prescription rate of zolpidem, this issue is of vital importance in terms of the drug's efficacy and patients' safety.

However, one issue that was not addressed in the discussion of this interesting paper is that of the association between the patient's sex and the endocrine specificity of zolpidem - as if zolpidem pharmacokinetics is a genderindependent factor. Based on current knowledge, the pharmacokinetics of zolpidem seems to be related to endocrine factors associated with CYP3A4 metabolism. As such, low plasma concentrations of free testosterone may contribute to lower CYP3A activity, with women achieving up to $50 \%$ higher zolpidem plasma levels, while exposure to testosterone activates the biotransformation via CYP3A [2]. This effect is conspicuous in the relative higher incidence of adverse drug reactions with zolpidem in women [3].

The conclusions of the study reported in the paper are valid for the model study on male subjects. It would have been interesting, however, if the discussion were to have included the exciting element of endocrine-related differences in zolpidem action.

Conflict of interest statement The authors declare that they have no conflict of interest.

Open Access This article is distributed under the terms of the Creative Commons Attribution Noncommercial License which permits any noncommercial use, distribution, and reproduction in any medium, provided the original author(s) and source are credited.

\section{References}

1. Polasek TM, Sadagopal JS, Elliot DJ, Miners JO (2010) In vitro-in vivo extrapolation of zolpidem as a perpetrator of metabolic interactions involving CYP3A. Eur J Clin Pharmacol 66:275-283

2. Olubodun JO, Ochs HR, von Moltke LL, Roubenoff R, Hesse LM, Harmatz JS, Shader RI, Greenblatt DJ (2003) Pharmacokinetic properties of zolpidem in elderly and young adults: possible modulation by testosterone in men. Br J Clin Pharmacol 56:297-304

3. Cubała WJ, Landowski J, Wichowicz HM (2008) Zolpidem abuse, dependence and withdrawal syndrome: sex as susceptibility factor for adverse effects. Br J Clin Pharmacol 65:444-445

W. J. Cubała $(\bowtie) \cdot$ M. Wiglusz $\cdot$ A. Burkiewicz $\cdot$

M. Gałuszko-Węgielnik

Department of Psychiatry, Medical University of Gdańsk,

Dębinki 7 St. Build. 25,

80-952 Gdańsk, Poland

e-mail: cubala@gumed.edu.pl 